\title{
Epidemiology of proximal humerus fractures
}

\author{
Sandra Iglesias-Rodríguez (iD, Diego Matías Domínguez-Prado @D, Alejandro García-Reza, \\ Daniel Fernández-Fernández, Elena Pérez-Alfonso, Javier García-Piñeiro and Manuel Castro-Menéndez@
}

\section{Introduction}

Proximal humerus fractures (PHF) are very common and a serious health problem [1]. They are the seventh most frequent fractures in adults [2]. Their prevalence varies from 4 to $10 \%$ of all fractures, according to several studies conducted in different populations [3]. Their treatment is sometimes controversial and some cases may be technically challenging. The incidence rate of these fractures shows considerable variation depending on the geographical area and the year of the study $[4,5]$. This rate has been suggested to be increasing along with the increase of elderly patients [6-8].

In order to plan health prevention protocols and to establish economic models in this field, up-to-date epidemiological data are necessary [1,9]. Although several epidemiological studies on PHF have been conducted in Europe [1, 4-7, 9-13], few have included both inpatients and outpatients $[1,3,4,9]$. No recent study of this kind has been found in the Iberian Peninsula nor in other southern European countries.

The aim of this study is to analyse PHFs from an epidemiologic and descriptive perspective, including the specific characteristics of the patients who suffer them, their incidence rate, the type of fracture and the methods used for treatment, and to compare these data with the available records of other countries.

\section{Material and methods}

Vigo is a Spanish city located in the northwest of the Iberian Peninsula, in the province of Pontevedra, Autonomous Community of Galicia. With a population of 295,364 inhabitants, it is the most populated city of

\footnotetext{
*Correspondence: sandra.iglesias.rodriguez@sergas.es

Servicio de Cirugía Ortopédica y Traumatología, Complejo Hospitalario Universitario de Vigo (Pontevedra), Estrada de Clara Campoamor, 341, 36213, Vigo, Pontevedra, Spain
}

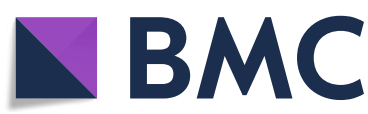

(c) The Author(s). 2021 Open Access This article is licensed under a Creative Commons Attribution 4.0 International License, which permits use, sharing, adaptation, distribution and reproduction in any medium or format, as long as you give appropriate credit to the original author(s) and the source, provide a link to the Creative Commons licence, and indicate if changes were made. The images or other third party material in this article are included in the article's Creative Commons licence, unless indicated otherwise in a credit line to the material. If material is not included in the article's Creative Commons licence and your intended use is not permitted by statutory regulation or exceeds the permitted use, you will need to obtain permission directly from the copyright holder. To view a copy of this licence, visit http://creativecommons.org/licenses/by/4.0/. The Creative Commons Public Domain Dedication waiver (http://creativecommons.org/publicdomain/zero/1.0/) applies to the data made available in this article, unless otherwise stated in a credit line to the data. core of a metropolitan area which comprises other fourteen municipalities, with a total population of 480,525 inhabitants. The Vigo University Hospital Complex (CHUVI) sees patients living in this metropolitan area.

A retrospective, observational study was conducted including all patients over 18 years of age who were admitted into the CHUVI A\&E department and diagnosed with PHF between January 1, 2016, and December 31, 2018.

Data were recorded as follows. All patients who were admitted into the emergency department in CHUVI and needed medical care provided by Trauma and Orthopedics (T\&O) were coded and divided into two groups: those with upper-limb involvement and those with lower-limb/spine involvement. The visits with upperlimb pathology recorded were subsequently revised and patients diagnosed with PHF were identified. Patients meeting these requirements but from outside the hospital's sphere of influence were excluded from the study.

A standard imaging-test protocol for shoulder injuries was originally performed to all patients with suspected PHF. The protocol consists of an anterior-posterior $\mathrm{x}$ ray (with the tangential central ray onto the glenoid surface) and a Velpeau axillary projection (with the patient's arm in internal rotation and the ray from cranial to caudal with the patient leaning backwards). In cases where a complex fracture was identified in the $\mathrm{x}$-ray, a computed tomography $(\mathrm{CT})$ was requested.

The following data were recorded from our patient selection: gender, age, laterality, type of trauma (high-energy traumas which included sports accidents, traffic accidents, falls from heights of more than $2 \mathrm{~m}$, or lowenergy trauma which included fall from standing height or syncope), season of the year when the fracture happened, pre-existing comorbidities (cardiovascular, 
neurological and/or psychiatric illness, alcohol abuse and smoking, confirmed diagnosis of osteoporosis, diabetes mellitus, obesity, malignancies, rheumatological diseases, endocrine diseases, and other metabolic disorders), and type of treatment for each PHF.

We reviewed the $\mathrm{x}$-ray and CT scan of all patients in order to classify them according to the three AO-OTA [14] types (A-C), its nine groups (A1-C3), and the number of PHF parts according to the Neer classification [15] (types I-V).

Data collection was carried out by five orthopaedic surgeons and further analysed by an independent observer.

The total number and the gender and age distributions of the population at risk for each year of the study period were obtained from the official CHUVI website (available at: https://xxivigo.sergas.gal/Paxinas/web. aspx ?tipo $=$ paxtxt\&idLista $=3 \&$ idContido $=272 \&$ migtab $=$ 272\&idTax $=850$ )

The incidence rate is a measure that reflects the risk of developing a new disease over a specified time period [16]. In this particular case, it measures a person's risk of suffering a PHF within the period of 1 year. The incidence rate is calculated as follows [17]:

Incidence rate $=\frac{\text { Number of events occurring during } a \text { specific time period }}{\text { Population at risk over } a \text { specified time period }} \times 10^{\mathrm{n}}$

In this study, the number of new events was the annual average number of PHF cases that occurred between 2016 and 2018. The population at risk was estimated using the median interval of the population during the specified time period (2016-2018). The gross incidence rate and gender-specific and age-specific incidence rates were calculated using age ranges per 100,000 inhabitants per year.

The study was approved by the Hospital/Regional Ethics Committee. The researchers conducted the study in accordance with the principles of the Declaration of Helsinki. The study was developed according to the protocol and in compliance with the standards of good clinical practice, as described in the guidelines of the International Council for Harmonisation (ICH) on good clinical practice.

\section{Statistical analysis}

The statistical analysis was carried out using the IBM software SPSS Statistics ${ }^{\oplus}$ v22. Continuous variables were described by using the mean, the standard deviation, and minimum and maximum values. Discrete variables were described using frequency distribution and percentages.

In the bivariate analysis, the Student-Fisher $t$ test was used for continuous variables and chi-squared test was used for categorical variables. Pearson's and Spearman's correlation coefficients were used for the association between variables. Differences were considered significant if $p<0.05$.

\section{Results}

In the period under review, there were 638 fractures (192 in 2016, 213 in 2017, and 233 in 2018). There were 7 patients (5 women and 2 men) who suffered two PHF but in periods of more than 6 months apart (4 patients in the contralateral shoulder and 3 in the ipsilateral shoulder), so they were considered as independent cases. In no case, a bilateral PHF was registered in the same visit to the emergency department.

\section{Age and gender}

The sample included 495 women (77.6\%) and 143 men (22.4\%), with a ratio of 3.4:1. By subdividing patients into groups sorted by decade, there was a female to male ratio of 1:1 up to 50 years old, which evolved to $4: 1$ above that age. A statistically significant association was found between the variables age and gender $(p<0.001)$.

Average patient age was $70.4 \pm 12.2$ years (minimum 18 and maximum 101 years). By subdividing into groups by 5 -year periods (Fig. 1), a progressive increase was observed up to 60 years old, which remained similar from this decade up to 90 years old. Beyond the age of 90 , the percentage decreased again. Octogenarians (80 to 89 years old) were the largest group (26.8\%). The cumulative percentage of patients aged 60 or older accounted for $78.8 \%$ of the sample.

\section{Affected side}

The right side was affected 330 times (258 women and 72 men), which amounts to $51.7 \%$, while the left was involved 308 times (48.3\%). There was no statistically significant association between laterality and gender $(p=$ 0.7).

\section{Injury mechanism}

Only in 3.6\% of cases (23 patients) was there highenergy trauma (13 women and 10 men), while the rest (96.4\%) were low energy. A statistically significant association between the type of trauma and age was observed, grouped by 5 -year periods $(p<0.001)$. Most high-energy injuries $(73.9 \%)$ occurred in patients under 60 , while only $20.7 \%$ of low-energy injuries were recorded in this age range. We have also found a statistically significant association between the type of trauma and the type of treatment provided, since $43.5 \%$ of highenergy fractures were operated on, while only $18.7 \%$ of low-energy injuries needed surgery $(p<0.001)$. 


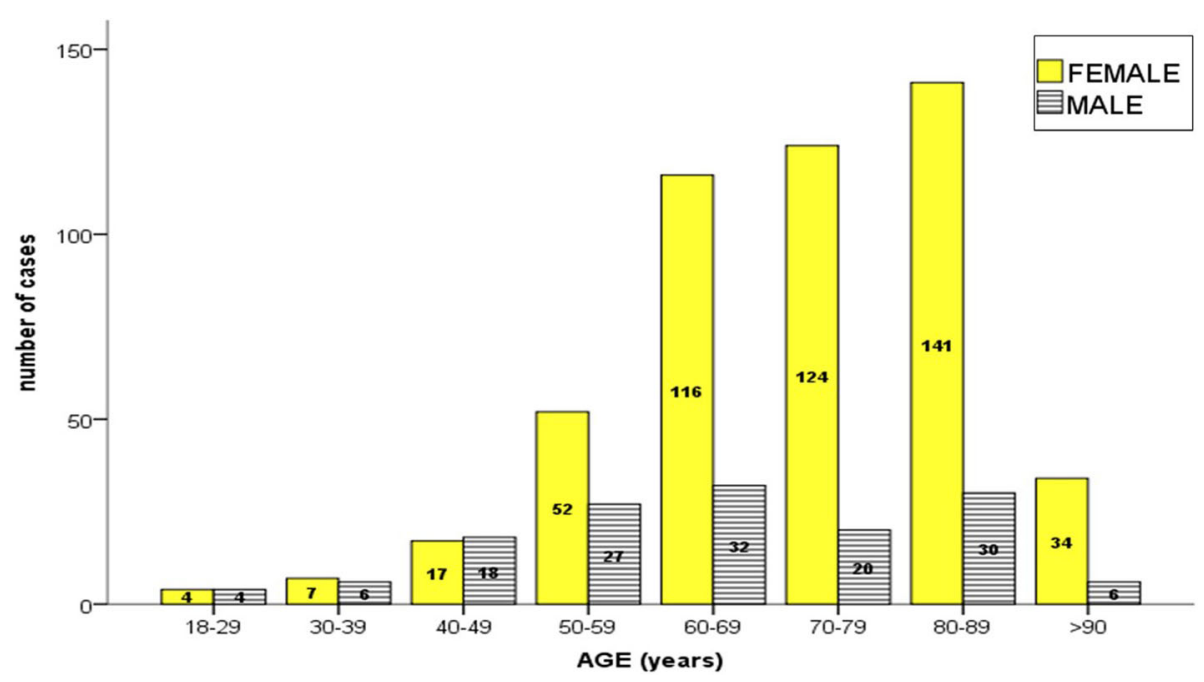

Fig. 1 Number of cases according to age

\section{Seasonal variation}

The season when there were more fractures was $\mathrm{Au}-$ tumn, with 179 fractures (28.14\%), followed by Spring with 166 cases (26\%), with Winter with the lowest number of fractures recorded (134 fractures, $21 \%)$. No statistically significant difference was found between them $(p$ $=0.8$ ). There was no statistically significant association between the season when the fracture occurred and gender $(p=0.4)$, age $(p=0.3)$, type of trauma $(p=0.6)$, or with the AO-OTA [14] $(p=0.6)$ or Neer [15] $(p=0.1)$ classifications (Table 1).

\section{Comorbidities}

A total of 112 (17.6\%) had no comorbidity, 324 (50.8\%) had one or two pathologies, and 202 (30.9\%) had three or more. The most frequent pathology was cardiovascular disease which occurred in $51.7 \%$ of patients (330 cases) (Fig. 2). We found a statistically significant association between the presence of comorbidity and the age of patients $(p<0.001)$ - the patients over 65 years old represent $76.2 \%$ of those who have some kind of pathology and $82 \%$ of patients of the sample with multiple pathological problems. There is also a statistically significant association ( $p=$ 0.004 ) between the existence of pathology and gender, with women accounting for $80 \%$ of patients with some kind of pathology in our sample and $86.6 \%$ of patients with many diseases.

Only $10.2 \%$ of patients were under treatment for osteoporosis (64 women and 1 man). This factor was not significantly associated with the type of trauma (high or low energy) ( $p=0.4$ ) or with the treatment carried out (conservative or surgical) $(p=0.5)$.

\section{Fracture classification}

According to the AO-OTA classification [14], 314 fractures were grouped into type A (49.2\%), 275 into type B (43.1\%) and 49 into type $C(7.7 \%)$. According to this classification, subgroup B1 ranked first with 226 cases (34.4\%), followed by A1 with 119 (18.1\%) and A2 with 111 (17\%). According to the Neer classification [15], there were 155 non-displaced or minimally displaced proximal humeral fractures (24.3\%), 206 two-part displaced proximal humeral fractures (32.3\%), 197 threepart fractures (30.9\%), 44 four-part fractures (6.9\%), and finally, in 36 cases, fracture was associated with a glenohumeral dislocation (5.6\%). We have not found any statistically significant association between gender and the AO-OTA classification $(p=0.1)$ or the Neer classification $(p=0.8)$. The type of trauma did not show a statistically significant association with the AO-OTA classification $(p=0.2)$ or with the Neer classification ( $p$ $=0.9$ ), as the diagnosis of osteoporosis did not show it either ( $p=0.4$ and $p=0.5$ respectively). However, there was certainly a statistically significant association between these two PHF classifications and age grouped by decades $(p=0.02$ for AO-OTA and $p=0.04$ for Neer) and also with the type of treatment performed in each patient $(p<0.001$ in both classifications) (Table 1).

\section{Type of treatment}

A total of 125 patients (19.6\%) underwent surgical treatment and the others were treated conservatively. Of the patients operated, 44 had a type-A fracture according to the AO-OTA classification [14] (35.2\%), 44 other patients had type-B PHF, and 37 type C (29.6\%). According to the NEER classification [15], 4 patients had a type-I 
Table 1 Patients of study divided by sex, age range, type of treatment, and mechanism of injury according to AO-OTA [14] and Neer [15] classifications. ( $y$, years old; $N$, number of cases; \% group, percentage cases within this AO-OTA group or NEER group classification; \% age, percentage cases within this range of age)

\begin{tabular}{|c|c|c|c|c|c|c|c|c|c|c|c|c|c|}
\hline & & & & \multicolumn{3}{|c|}{$\begin{array}{l}\text { AO_OTA } \\
\text { classification }\end{array}$} & \multirow[t]{2}{*}{ All } & \multicolumn{5}{|c|}{ Neer classification } & \multirow[t]{2}{*}{ All } \\
\hline & & & & $A$ & B & $\mathrm{C}$ & & $\begin{array}{l}\text { Non } \\
\text { displaced }\end{array}$ & $\begin{array}{l}\text { 2- } \\
\text { part }\end{array}$ & $\begin{array}{l}\text { 3- } \\
\text { part }\end{array}$ & 4-part & $\begin{array}{l}\text { Fracture- } \\
\text { dislocation }\end{array}$ & \\
\hline \multirow{6}{*}{\multicolumn{2}{|c|}{ Female }} & \multirow[t]{3}{*}{$<50 y$} & $\mathrm{~N}$ & 26 & 4 & 1 & 31 & 17 & 11 & 2 & 1 & 0 & 31 \\
\hline & & & $\%$ age & $83.9 \%$ & $12.9 \%$ & $3.2 \%$ & $100 \%$ & $54.8 \%$ & $35.5 \%$ & $6.5 \%$ & $3.2 \%$ & $0.0 \%$ & $100 \%$ \\
\hline & & & $\begin{array}{l}\% \\
\text { group }\end{array}$ & $11.1 \%$ & $1.8 \%$ & $2.6 \%$ & $6.3 \%$ & $14.8 \%$ & $6.9 \%$ & $1.2 \%$ & $3.0 \%$ & $0.0 \%$ & $6.3 \%$ \\
\hline & & \multirow[t]{3}{*}{$>50 y$} & $N$ & 208 & 219 & 37 & 464 & 98 & 149 & 159 & 32 & 26 & 464 \\
\hline & & & $\%$ age & $44.8 \%$ & $47.2 \%$ & $8.0 \%$ & $100 \%$ & $21.1 \%$ & $32.1 \%$ & $34.3 \%$ & $6.9 \%$ & $5.6 \%$ & $100 \%$ \\
\hline & & & $\begin{array}{l}\% \\
\text { group }\end{array}$ & $88.9 \%$ & $98.2 \%$ & $97.4 \%$ & $93.7 \%$ & $85.2 \%$ & $93.1 \%$ & $98.8 \%$ & $97.0 \%$ & $100.0 \%$ & $93.7 \%$ \\
\hline \multirow{6}{*}{\multicolumn{2}{|c|}{ Male }} & \multirow[t]{3}{*}{$<50 y$} & $\mathrm{~N}$ & 21 & 7 & 1 & 29 & 13 & 8 & 5 & 1 & 2 & 29 \\
\hline & & & $\%$ age & $72.4 \%$ & $24.1 \%$ & $3.4 \%$ & $100 \%$ & $44.8 \%$ & $27.6 \%$ & $17.2 \%$ & $3.4 \%$ & $6.9 \%$ & $100 \%$ \\
\hline & & & $\begin{array}{l}\% \\
\text { group }\end{array}$ & $26.3 \%$ & $13.5 \%$ & $9.1 \%$ & $20.3 \%$ & $32.5 \%$ & $17.4 \%$ & $13.9 \%$ & $9.1 \%$ & $20.0 \%$ & $20.3 \%$ \\
\hline & & \multirow[t]{3}{*}{$>50 y$} & $\mathrm{~N}$ & 59 & 45 & 10 & 114 & 27 & 38 & 31 & 10 & 8 & 114 \\
\hline & & & $\%$ age & $51.8 \%$ & $39.5 \%$ & $8.8 \%$ & $100 \%$ & $23.7 \%$ & $33.3 \%$ & $27.2 \%$ & $8.8 \%$ & $7.0 \%$ & $100 \%$ \\
\hline & & & $\begin{array}{l}\% \\
\text { group }\end{array}$ & $73.8 \%$ & $86.5 \%$ & $90.9 \%$ & $79.7 \%$ & $67.5 \%$ & $82.6 \%$ & $86.1 \%$ & $90.9 \%$ & $80.0 \%$ & $79.7 \%$ \\
\hline \multirow[t]{12}{*}{ Treatment } & \multirow[t]{6}{*}{ Conservative } & \multirow[t]{3}{*}{$<50 y$} & $\mathrm{~N}$ & 35 & 7 & 0 & 42 & 30 & 8 & 3 & 0 & 1 & 42 \\
\hline & & & $\%$ age & $83.3 \%$ & $16.7 \%$ & $0.0 \%$ & $100 \%$ & $71.4 \%$ & $19.0 \%$ & $7.1 \%$ & $0.0 \%$ & $2.4 \%$ & $100 \%$ \\
\hline & & & $\begin{array}{l}\% \\
\text { group }\end{array}$ & $13.0 \%$ & $3.0 \%$ & $0.0 \%$ & $8.2 \%$ & $19.9 \%$ & $4.9 \%$ & $1.9 \%$ & $0.0 \%$ & $3.3 \%$ & $8.2 \%$ \\
\hline & & \multirow[t]{3}{*}{$>50 y$} & $\mathrm{~N}$ & 235 & 224 & 12 & 471 & 121 & 155 & 153 & 13 & 29 & 471 \\
\hline & & & $\%$ age & $49.9 \%$ & $47.6 \%$ & $2.5 \%$ & $100 \%$ & $25.7 \%$ & $32.9 \%$ & $32.5 \%$ & $2.8 \%$ & $6.2 \%$ & $100 \%$ \\
\hline & & & $\begin{array}{l}\% \\
\text { group }\end{array}$ & $87.0 \%$ & $97.0 \%$ & $100 \%$ & $91.8 \%$ & $80.1 \%$ & $95.1 \%$ & $98.1 \%$ & $100.0 \%$ & $96.7 \%$ & $91.8 \%$ \\
\hline & \multirow[t]{6}{*}{ Surgery } & \multirow[t]{3}{*}{$<50 y$} & $\mathrm{~N}$ & 12 & 4 & 2 & 18 & 0 & 11 & 4 & 2 & 1 & 18 \\
\hline & & & $\%$ age & $66.7 \%$ & $22.2 \%$ & $11.1 \%$ & $100 \%$ & $0 \%$ & $61.1 \%$ & $22.2 \%$ & $11.1 \%$ & $5.6 \%$ & $100 \%$ \\
\hline & & & $\begin{array}{l}\% \\
\text { group }\end{array}$ & $27.3 \%$ & $9.1 \%$ & $5.4 \%$ & $14.4 \%$ & $0 \%$ & $25.6 \%$ & $9.8 \%$ & $6.5 \%$ & $16.7 \%$ & $14.4 \%$ \\
\hline & & \multirow[t]{3}{*}{$>50 y$} & $\mathrm{~N}$ & 32 & 40 & 35 & 107 & 4 & 32 & 37 & 29 & 5 & 107 \\
\hline & & & $\%$ age & $29.9 \%$ & $37.4 \%$ & $32.7 \%$ & $100 \%$ & $3.7 \%$ & $29.9 \%$ & $34.6 \%$ & $27.1 \%$ & $4.7 \%$ & $100 \%$ \\
\hline & & & $\begin{array}{l}\% \\
\text { group }\end{array}$ & $72.7 \%$ & $90.9 \%$ & $94.6 \%$ & $85.6 \%$ & $100 \%$ & $74.4 \%$ & $90.2 \%$ & $93.5 \%$ & $83.3 \%$ & $85.6 \%$ \\
\hline \multirow{6}{*}{\multicolumn{2}{|c|}{ Mechanics }} & \multirow{3}{*}{$\begin{array}{l}\text { High } \\
\text { energy }\end{array}$} & $\mathrm{N}$ & 15 & 6 & 2 & 23 & 5 & 9 & 5 & 2 & 2 & 23 \\
\hline & & & $\begin{array}{l}\% \text { Hihg } \\
\text { E }\end{array}$ & $65.2 \%$ & $26.1 \%$ & $8.7 \%$ & $100 \%$ & $21.7 \%$ & $39.1 \%$ & $21.7 \%$ & $8.7 \%$ & $8.7 \%$ & $100 \%$ \\
\hline & & & $\begin{array}{l}\% \\
\text { group }\end{array}$ & $4.8 \%$ & $2.2 \%$ & $4.1 \%$ & $3.6 \%$ & $3.2 \%$ & $4.4 \%$ & $2.5 \%$ & $4.5 \%$ & $5.6 \%$ & $3.6 \%$ \\
\hline & & \multirow{3}{*}{$\begin{array}{l}\text { Low } \\
\text { energy }\end{array}$} & $\mathrm{N}$ & 299 & 269 & 47 & 615 & 150 & 197 & 192 & 42 & 34 & 615 \\
\hline & & & $\begin{array}{l}\% \text { Low } \\
\text { E }\end{array}$ & $48.6 \%$ & $43.7 \%$ & $7.6 \%$ & $100 \%$ & $24.4 \%$ & $32.0 \%$ & $31.2 \%$ & $6.8 \%$ & $5.5 \%$ & $100 \%$ \\
\hline & & & $\begin{array}{l}\% \\
\text { group }\end{array}$ & $95.2 \%$ & $97.8 \%$ & $95.9 \%$ & $96.4 \%$ & $96.8 \%$ & $95.6 \%$ & $97.5 \%$ & $95.5 \%$ & $94.4 \%$ & $96.4 \%$ \\
\hline
\end{tabular}




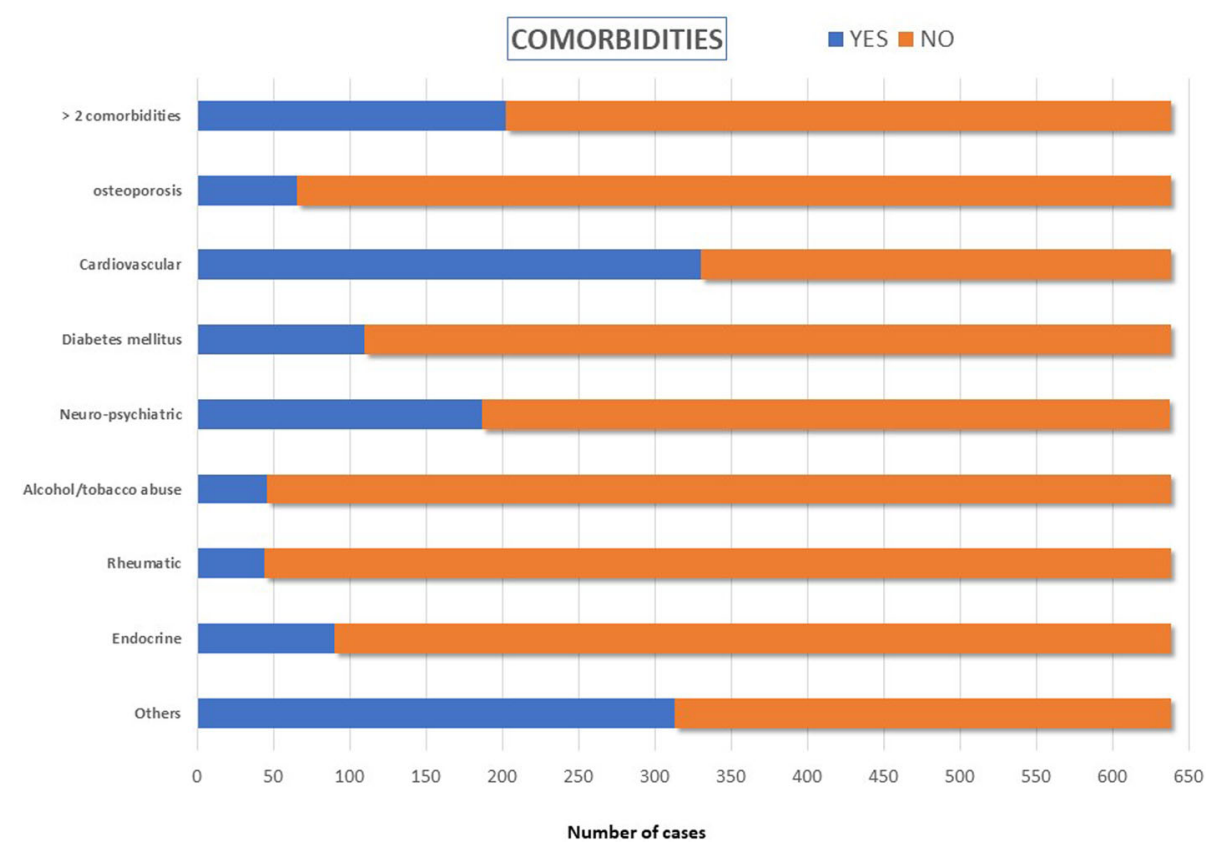

Fig. 2 Comorbidities asocciated with fracture cases

fracture (all of these patients another ipsilateral fracture associated which required surgical treatment), 43 patients had a two-part fracture (20.9\% of this group), 41 a three-part fracture (20.8\% of the group), 31 a 4-part fracture (70.5\% the group), and only $16.7 \%$ of fracturesdislocation (6 patients) were surgically treated (Table 1$)$.

The most used surgical treatment was locking plates in 52 patients $(41.6 \%)$, followed by reverse total shoulder arthroplasty in 36 cases (28.8\%) and intramedullary nailing in 16 cases (12.8\%). The most used fixation method in AO-OTA type B PHFs were locking plates $(59.1 \%$ of the type B PHF), whereas in type $\mathrm{C}$ arthroplasties were the most common procedure (67.6\% of the type $C$ ) and in type A both locking plates and intramedullary nailing ranked first (31.8\% both). As regards the NEER classification, locking plates were used on three occasions and an intramedullary nail once to treat minimally displaced fractures; the most used treatment in two-part fractures were both locking plates and intramedullary nails (30\% each for this PHF type), locking plates for 3-part fractures (56\% of 3-part fractures), and reverse total shoulder arthroplasty for 4-part fractures (67.7\%) of this group. Fractures-dislocations were treated surgically with locking plates on two occasions and with arthroplasty on three. Cannulated screws were also used as a fixation method in 13 cases (10 cases of 2-part fractures affecting the greater tubercle and 3 cases of 3-part fractures) and Kirschner needles in 8 cases (3 cases of 2-part fractures and 5 of 3-part fractures). We found a statistically significant association between the NEER classification and the method of osteosynthesis used $(p<0.001)$.

\section{Incidence}

The risk population over 18 years old of the CHUVI healthcare area was estimated at 353,403 people/year between January 1, 2016, and December 31, 2018. There were 168,663 men and 184,739 women per year when disaggregating gender.

In the period studied, there were 7698 emergency room visits because of musculoskeletal conditions that were treated and followed up by the Upper Limb Unit of the CHUVI T\&O department; 4319 of these were fractures (56.1\%), which amounts to an annual incidence rate of 293.3 fractures per 100,000 inhabitants and year. As regards PHFs, we calculated an incidence rate of 60.1 fractures per 100,000 inhabitants and year. We calculated a gender-disaggregated incidence rate of 89.3 fractures per 100,000 women/year and 28.2 fractures per 100,00 men/year. The incidence distributed by decades is shown in Fig. 3 and Table 2.

\section{Discussion}

In our study population, PHF fractures were the third most frequent in the upper limb after distal radius fractures (DRF) and metacarpal and phalangeal fractures and account for $14.7 \%$ of all fractures of this anatomical region and $8.2 \%$ of the global cause of emergencies due to upper limb pathologies during the period of study. In the article published in 2000 by Court-Brown and Caesar [4], with a population similar to ours, PHFs were 9.6\% of upper limb fractures, in third place after distal radius fractures and metacarpal and phalangeal fractures. 


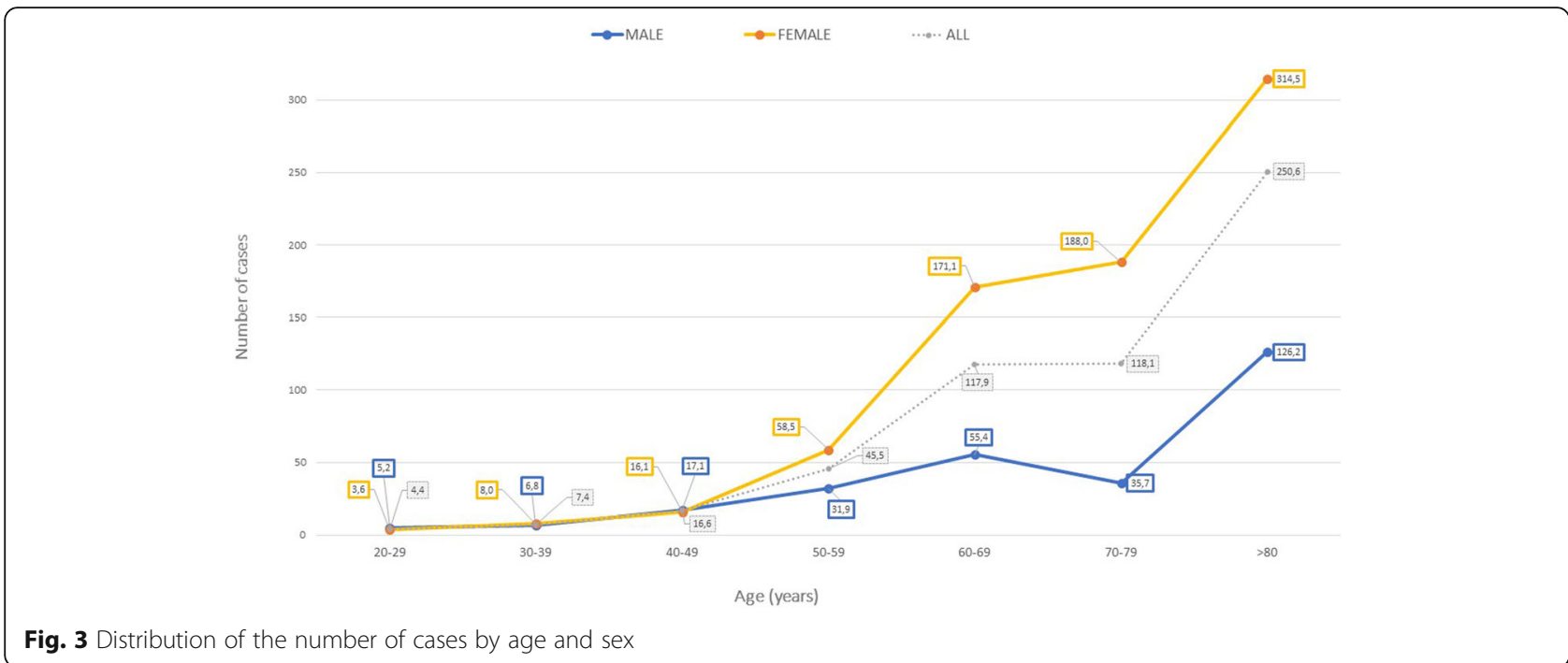

One of the most interesting findings of our study is that the incidence rate observed in our sample (60.1 per 100,000 inhabitants/year) was lower than that published in other studies in Northern Europe [5, 18, 20, 22], but similar to that published in Scotland by Court-Brown and Caesar [4] (63 per 100,000 inhabitants/year) where patients treated both surgically and conservatively were included. These findings apply both for the analysis of the total sample and the segregation by age or gender and also includes both inpatients and outpatients.

We have also found variations in the incidence rate per age range referenced in other studies (Table 1). All these data might lead us to conclude that the PHF incidence rate may vary depending on the geographical area, activity, health, and care provided to the elderly, although the data from these studies cannot be compared rigorously. Regarding the age-adjusted incidence rate of our sample, it is most remarkable that higher values are observed with respect to the studies that only consider inpatients [7, 11, 19, 21, 22]. In contrast, the values in our sample were lower than the studies including both inpatients and outpatients $[1,4,5,10,12,18]$. Of course, if a portion of the patients treated is not recorded, the incidence rate tends to be underestimated, and perhaps to an even greater extent today, since patients tend to be treated mainly on an outpatient basis.

In line with the articles published in the literature [113], we have observed a significant increase in the PHF incidence in people over 50 years old, especially in women (Fig. 1). Most of these fractures are due to low energy injuries, mainly due to falls from standing height. In our study, more than $50 \%$ of the population with PHF was over 70 years old, mostly women (84.2\%). Up to 50 years of age, the female to male ratio was $1: 1$ and in people that were older than 50 , the ratio became $4: 1$. This can be explained by the increased risk of falls in the older population, the unpredictability of the trauma, the greater likelihood to have osteoporosis, and by women's greater life expectancy [3]. In 2010, Hernlund et al. [21] estimated that $54 \%$ of the total population of the European Union (EU) were women and that they had suffered two thirds of all accidental fractures. During the period of study, there was a similar distribution (53\% women and $47 \%$ of men) in our healthcare area. Above 75 years of age, there were nearly $33 \%$ more women than men.

Similarly to other studies published $[2,3,5]$, no statistically significant differences were found regarding the affected side, either analysing the total sample or segregating it by age or gender.

According to Roux et al. [2], there are two major risk factors for osteoporotic fractures and in particular for PHFs. The first risk is bone fragility followed by the risk of falling. The more fragile bones are, the more serious the fracture is [12]. In 2011, it was estimated that the prevalence of osteoporosis in the EU was $5.5 \%$ of the population, and in Spain, it was $5.4 \%(6.8 \%$ in men and $22.6 \%$ in women) [21]. In 2011, Calvo et al. [23] published a multicentre prospective study on 5147 postmenopausal women over the age of 50 with osteoporotic fractures in Spain. These authors concluded that PHFs accounted for $17.5 \%$ of the total number of osteoporotic fractures in this population and that only 1521 women (29.5\%) took treatment for osteoporosis. In our study, $6.5 \%$ of patients with PHF (64 women and 1 man) were taking treatment for osteoporosis at the time they suffered a fall, and all of them were over 50 . This accounts for $13.7 \%$ of women over the age of 50 , which represents a significantly lower figure than the data published by Calvo et al. [24] and Hemlund et al. [21], although it is likely that this pathology is underdiagnosed in our population. Despite taking treatment for osteoporosis, three 
Table 2 Annual incidence rates of humerus fractures (per 100,000 inhabitants-year) in our study in comparison with countries from different geographic regions of Europe

\begin{tabular}{|c|c|c|c|c|c|c|c|}
\hline Author, year publication & $\begin{array}{l}\text { Origin of study } \\
\text { Number of } \\
\text { patients (N) }\end{array}$ & $\begin{array}{l}\text { Study } \\
\text { period }\end{array}$ & $\begin{array}{l}\text { Origin of patient } \\
\text { database }\end{array}$ & $\begin{array}{l}\text { Age of patients, } \\
\text { years }\end{array}$ & Sex & $\begin{array}{l}\text { Annual rate }\left(\times 10^{5}\right. \\
\mathrm{h} / \mathrm{a})^{*}\end{array}$ & $\begin{array}{l}\text { Our } \\
\text { study } \\
2016- \\
2018 \\
N=638 \\
\end{array}$ \\
\hline Kristiansen et al. [8], 1987 & $\begin{array}{l}\text { Denmark } \\
N=565\end{array}$ & 1983 & $\begin{array}{l}\text { Inpatients and } \\
\text { outpatients }\end{array}$ & $\begin{array}{l}20-29 \\
30-39 \\
40-49 \\
50-59 \\
60-69 \\
70-79 \\
>80\end{array}$ & $\begin{array}{l}\text { Female } \\
\text { Male } \\
\text { Female } \\
\text { Male } \\
\text { Female } \\
\text { Male } \\
\text { Female } \\
\text { Male } \\
\text { Female } \\
\text { Male } \\
\text { Female } \\
\text { Male } \\
\text { Female } \\
\text { Male }\end{array}$ & $\begin{array}{l}4 \\
2 \\
16 \\
33 \\
61 \\
33 \\
111 \\
32.5 \\
208 \\
98 \\
359 \\
115 \\
502 \\
182\end{array}$ & $\begin{array}{l}3.5 \\
5.1 \\
7.9 \\
6.8 \\
16 \\
17.8 \\
58.4 \\
31.8 \\
171 \\
55.4 \\
188 \\
35.7 \\
314.4 \\
126.1\end{array}$ \\
\hline Lind et al. [18], 1989 & $\begin{array}{l}\text { Denmark } \\
N=730\end{array}$ & 1980-1984 & $\begin{array}{l}\text { Inpatients and } \\
\text { outpatients }\end{array}$ & $\geq 18$ & All & 73 & 60.1 \\
\hline $\begin{array}{l}\text { Court-Brown et al. [10], } \\
2001\end{array}$ & $\begin{array}{l}\text { Scotland } \\
N=1027\end{array}$ & 1992-1996 & $\begin{array}{l}\text { Inpatients and } \\
\text { outpatients }\end{array}$ & $\begin{array}{l}20-29 \\
30-39 \\
40-49 \\
50-59 \\
60-69\end{array}$ & $\begin{array}{l}\text { Female } \\
\text { Male } \\
\text { Female } \\
\text { Male } \\
\text { Female } \\
\text { Male } \\
\text { Female } \\
\text { Male } \\
\text { Female } \\
\text { Male } \\
\text { Female } \\
\text { Male } \\
\text { Female } \\
\text { Male } \\
\text { Female } \\
\text { Male }\end{array}$ & $\begin{array}{l}4 \\
5 \\
4 \\
15 \\
20 \\
20 \\
45 \\
28 \\
96 \\
34 \\
188 \\
58 \\
260 \\
109 \\
139 \\
159\end{array}$ & $\begin{array}{l}3.5 \\
5.1 \\
7.9 \\
6.8 \\
16 \\
17.8 \\
58.4 \\
31.8 \\
171 \\
55.4 \\
188 \\
35.7 \\
(>80) \\
314.4 \\
(>80) \\
126.1\end{array}$ \\
\hline Maravicz et al. [19], 2005 & $\begin{array}{l}\text { France } \\
N=12262\end{array}$ & 2001 & Inpatients & $\begin{array}{l}46-65 \\
66-80 \\
>80\end{array}$ & $\begin{array}{l}\text { Female } \\
\text { Male } \\
\text { Female } \\
\text { Male } \\
\text { Female } \\
\text { Male }\end{array}$ & $\begin{array}{l}23.5 \\
17.3 \\
107 \\
29.8 \\
247.5 \\
78.5\end{array}$ & \begin{tabular}{l|}
39.8 \\
28.8 \\
241.8 \\
95.1 \\
234.2 \\
126.1
\end{tabular} \\
\hline Palvanen et al. [5], 2006 & Finland & $1970-2002$ & Inpatients & $\geq 60$ & All & $\begin{array}{l}32^{(1970)} \\
105^{(2002)}\end{array}$ & 148.9 \\
\hline & & & & & Femal & $\begin{array}{l}51^{(1970)} \\
129^{(2002)}\end{array}$ & 215.4 \\
\hline & & & & & Male & $\begin{array}{l}14^{(1970)} \\
48^{(2002)}\end{array}$ & 60.4 \\
\hline $\begin{array}{l}\text { Court-Brown and Caesar } \\
\text { [2], } 2006\end{array}$ & $\begin{array}{l}\text { Scotland } \\
N=337\end{array}$ & 2000 & $\begin{array}{l}\text { Inpatients and } \\
\text { outpatients }\end{array}$ & $\geq 14$ & All & 63 & 60.1 \\
\hline Péntek et al [7, 17], 2008 & $\begin{array}{l}\text { Hungary } \\
N=41556\end{array}$ & 1999-2003 & $\begin{array}{l}\text { Inpatients and } \\
\text { outpatients }\end{array}$ & $\begin{array}{l}65-69 \\
80-84\end{array}$ & $\begin{array}{l}\text { All } \\
\text { Female } \\
\text { Male } \\
\text { All } \\
\text { Female } \\
\text { Male }\end{array}$ & $\begin{array}{l}248 \\
366 \\
215 \\
632 \\
1151 \\
632\end{array}$ & \begin{tabular}{l|}
150.1 \\
188.1 \\
91.4 \\
214.1 \\
280.4 \\
106.2
\end{tabular} \\
\hline Dimai et al [9], 2013 & Austria & 1989-2008 & Inpatients & $\geq 50$ & $\begin{array}{l}\text { Female } \\
\text { Male }\end{array}$ & $\begin{array}{l}141 \text { to } 383 \\
112 \text { to } 222\end{array}$ & $\begin{array}{l}166.7 \\
50.2\end{array}$ \\
\hline Launonen et al. [3], 2015 & $\begin{array}{l}\text { Finland } \\
N=678\end{array}$ & 2006-2010 & $\begin{array}{l}\text { Inpatients and } \\
\text { outpatients }\end{array}$ & $\begin{array}{l}\geq 16 \\
20-29\end{array}$ & $\begin{array}{l}\text { All } \\
\text { Female } \\
\text { Male }\end{array}$ & $\begin{array}{l}82 \\
13 \\
14\end{array}$ & $\begin{array}{l}60.1 \\
3.5 \\
5.1\end{array}$ \\
\hline
\end{tabular}


Table 2 Annual incidence rates of humerus fractures (per 100,000 inhabitants-year) in our study in comparison with countries from different geographic regions of Europe (Continued)

\begin{tabular}{|c|c|c|c|c|c|c|c|}
\hline Author, year publication & $\begin{array}{l}\text { Origin of study } \\
\text { Number of } \\
\text { patients (N) }\end{array}$ & $\begin{array}{l}\text { Study } \\
\text { period }\end{array}$ & $\begin{array}{l}\text { Origin of patient } \\
\text { database }\end{array}$ & $\begin{array}{l}\text { Age of patients, } \\
\text { years }\end{array}$ & Sex & $\begin{array}{l}\text { Annual rate }\left(\times 10^{5}\right. \\
\mathrm{h} / \mathrm{a})^{*}\end{array}$ & $\begin{array}{l}\text { Our } \\
\text { study } \\
2016- \\
2018 \\
N=638\end{array}$ \\
\hline & & & & $\begin{array}{l}30-39 \\
40-49 \\
50-59\end{array}$ & $\begin{array}{l}\text { Female } \\
\text { Male } \\
\text { Female } \\
\text { Male } \\
\text { Female } \\
\text { Male }\end{array}$ & \multirow{2}{*}{$\begin{array}{l}18 \\
12 \\
39 \\
31 \\
112 \\
63 \\
193 \\
87 \\
296 \\
100 \\
379 \\
232\end{array}$} & \multirow{2}{*}{$\begin{array}{l}7.9 \\
6.8 \\
16 \\
17.8 \\
58.4 \\
31.8 \\
171 \\
55.4 \\
188 \\
35.7 \\
314.4 \\
126.1\end{array}$} \\
\hline & & & & $\begin{array}{l}60-69 \\
70-79 \\
>80\end{array}$ & $\begin{array}{l}\text { Female } \\
\text { Male } \\
\text { Female } \\
\text { Male } \\
\text { Female } \\
\text { Male }\end{array}$ & & \\
\hline Bergdahl et al. [1], 2016 & $\begin{array}{l}\text { Sweden } \\
N=2011\end{array}$ & 2011-2013 & $\begin{array}{l}\text { Inpatients and } \\
\text { outpatients }\end{array}$ & $\geq 16$ & All & 83 & 60.1 \\
\hline Sumrein et al. [20], 2017 & $\begin{array}{l}\text { Sweden } \\
N=98770\end{array}$ & 2001-2012 & $\begin{array}{l}\text { Inpatients and } \\
\text { outpatients }\end{array}$ & $\geq 18$ & $\begin{array}{l}\text { Female } \\
\text { Male }\end{array}$ & $\begin{array}{l}134.5^{(2001)} \\
174.6^{(2012)} \\
68.1^{(2001)} \\
49.2^{(2012)}\end{array}$ & $\begin{array}{l}89.3 \\
28.2\end{array}$ \\
\hline Kannus et al. [21], 2017 & Finland & $1970-2015$ & Inpatients & $\geq 80$ & Female & $\begin{array}{l}87^{(1970)} \\
297^{(2015)}\end{array}$ & 314.4 \\
\hline Klug et al. [22], 2019 & $\begin{array}{l}\text { Germany } \\
N=642556\end{array}$ & $2007-2016$ & Inpatients & $\geq 16$ & All & 74.2 & 60.1 \\
\hline
\end{tabular}

*( $\times 105$ h/a): per 100,000 inhabitants/year

women, who fell on two separate occasions more than six months apart, suffered two PHFs each.

It has been described that cardiovascular diseases can be a factor favouring the occurrence of falls [2]. Just over half of the sample (51.7\%) had cardiovascular disease, which is the most prevalent comorbidity in our study. Within that group, the cause of PHF in up to $98 \%$ of patients was a low-energy fall. Chu et al. [25] studied the risk factors associated to PHFs in patients older than 45 and concluded that falls, diabetes mellitus, and difficulty walking in low light are frequent aspects related to these types of fracture. However, Martinez-Huedo et al. [26] found that type- 2 diabetes mellitus was a risk factor. In our study, $17.2 \%$ of patients with PHF were (type 1 and type 2) diabetic while the estimated percentage in the Spanish general population older than 18 years of age is $13.8 \%$. It has also been suggested that epilepsy, depression, and dementia increase the risk of PHF. In our study, we have noted that $29.3 \%$ of the patients presented neurological or psychiatric diseases.

Almost all epidemiological studies showed seasonal variation in the frequency of PHF, with an increase of these fractures in winter $[1-3,5,12,18]$. The authors justify these variations on the grounds of weather conditions (for example rain, wind, snow, mud, and ice) and of fewer hours of sunlight in winter, which can increase the risk of falls, car accidents, or both.
In this study, we found neither differences in distribution of PHF with respect to season nor a statistical correlation when considering trauma mechanism, age, or gender with regard to the season. These variables appear to remain stable, probably due to our moderate oceanic climate.

Regarding the type of injury that caused the high or low-energy PHF, we have found a correlation between injury mechanism and age. In fact, as observed in other studies $[2,18]$, there was a bimodal distribution depending on the mechanism of energy and the patient's age (Fig. 3). Most high-energy injuries (65.2\%) happened to patients under the age of 55, while in this age range, only $12.3 \%$ suffered low-energy trauma. This is justified because the younger population is more likely to engage in contact sports, has more intense physical activity, and drives cars or rides motorcycles. In contrast, it is usual that low-energy injuries happen to older patients, considering the progressive decrease in bone strength as a result of ageing.

We have also found a statistically significant association between the type of trauma suffered and the type of treatment. As much as $43.5 \%$ of patients with highenergy PHFs underwent surgical treatment, while only $18.7 \%$ of patients with low-energy trauma needed surgery. However, as in the study of Bergdahl et al. [1], there was no statistically significant association between 
the injury mechanism and the type of fracture according to the AO-OTA classification [14] or the Neer classification [15]. Two reasons could justify this: first, because $26 \%$ of patients who suffered high-energy trauma had another fracture associated in the ipsilateral limb that required surgical treatment, although not all of them had a complex proximal humerus fracture, and secondly, because older women who suffer a low-energy fall usually have complex fractures due to their poor bone quality.

The severity of fractures increases as people age [2]. In his article in 1970, Neer [15] estimated that approximately $85 \%$ of all PHFs were not displaced (type I) fractures. However, much lower percentages of these type-I fractures (from 13 to 49\%) [3, 10, 11, 13, 18] have been found in recent studies, which is consistent with our data $(24.3 \%)$. Even so, in the studies of Court-Brown et al. [12] and of Roux et al. [2], type I was the most frequent, while in other studies such as those by Launonen et al. [5], Lidn et al. [18], and Barhs et al. [13], type II prevailed. In our study, if we split the sample between younger and older than 50 years old, we find that type I fracture is the most common in both young male and female, while type II fracture is the most common in older male and type III in older female. With regard to more complex fractures (three and four parts, including fracture-dislocation), we have found a higher proportion than Court-Brown et al. [12], Launonen et al. [5], and Roux et al. [2], although it is similar to what has been published in the Swedish registry [20] (Table 1).

In reference to the AO-OTA classification [14], CourtBrown et al. [12] and Bahrs et al. [13] reported a higher percentage of type-A fractures $(66 \%$ and $61 \%$, respectively), while in the study of Bergdahl et al. [1], there was a similar percentage in type $A$ and $B$ and lower in type C (45\%, 44\%, and $11 \%$, respectively). Type-A fractures were also the most frequent in our sample although the distribution was similar to what has been published by Bergdahl et al. [1] in their Swedish registry (49\%, 43\%, and $7.7 \%$, respectively). Statistically significant differences between the different types were also found. These authors have postulated the greater percentage of elderly patients in their sample as a possible explanation, because type-A fractures are more frequent in young patients while type $B$ and $C$ fractures increase with age. This is in line with our study because type $B$ and $C$ fractures account for only $21.6 \%$ of PHFs in people under 50. Another possible explanation in this change of fracture pattern could be related to imaging techniques. We have done the initial assessment and radiographic review in this study with digital $\mathrm{x}$-rays, which allow to enlarge images and to change contrast, so we have been able to detect fracture lines that may go unnoticed initially and, therefore, change the initial classification to type $\mathrm{B}$ or $\mathrm{C}$ fractures. However, it is important to keep in mind that these two classifications are subject to both wide interobserver and intraobserver variability [2].

Some important factors that influence decision making and the long-term clinical results in PHFs are the number of displaced parts and the patient's age. The increase in the number of complex fractures, along with improvements in the surgical material with the appearance of locking plates and reverse shoulder arthroplasty, have led to a relative increase of surgical treatment of up to $40 \%[8,23]$. However, this trend has not been supported by studies of high scientific evidence and, in fact, there is considerable variation in current clinical practice. The Cochrane Library review published in 2015 showed no differences between the surgical and conservative treatment for complex PHFs [23]. No statistically or clinically significant differences were found between the surgical and non-surgical treatment in the ProFHER randomised clinical trial [27] in patients with displaced PHFs or in the systematic review and meta-analysis carried out in 2015 by Rabbi et al. [28]. In our study, $75.7 \%$ of PHFs were displaced fractures. However, only $25 \%$ were treated surgically (20\% of Neer type II and $28 \%$ of the group of three or more parts, including fracturesdislocations). This lack of correlation shows how difficult it is to handle this type of patients, because of the bone quality and comorbidities in elderly patients. More than $40 \%$ of the patients in our study were older than 75 at the time of the fracture and more than $95 \%$ of these patients had some kind of associated pathology.

Like in other studies [20, 22], the most used surgical treatment was locking plates (47 cases) especially for 2part and 3-part fractures, followed by reverse total shoulder arthroplasty (36 cases), which was used most frequently in our study for treatment of 4-part PHFs. As we have mentioned before, the use of these treatments has increased rapidly in comparison to others, although it has not been possible to demonstrate that they are clearly better approaches [5, 23].

\section{Limitations and strengths of the study}

This study presents some limitations. The retrospective nature and the relatively small population in the study are a limitation, as well as the fact that the classification of fractures was carried out by five orthopaedic surgeons, which further increases the likelihood of finding high interobserver variability. As strengths of this study, we have been limited to the registration of one hospital where all the emergencies and urgencies of the abovementioned metropolitan area are treated, since it is accessible to the whole population because of the comprehensive healthcare system in Spain. Another strong point is that we have been able to collect all the PHFs that occurred in the above-mentioned area, including patients and outpatients and both surgical and non- 
surgical treatment. Due to these two strengths, we believe we have selected a representative sample of our region, and it might be extrapolated to the rest of the Spanish population for the epidemiological analysis of this pathology. Furthermore, no similar epidemiological studies have been published in Southern-Mediterranean European countries, which share similar lifestyle, nourishment, climate conditions, and life expectancy. Our results could resonate better with the epidemiology of PHF in these countries in comparison with northern and central European registries. However, besides this fact, comparisons with other studies should be made with caution, especially due to differences in the criteria for patient selection.

\section{Conclusions}

PHFs are a very frequent pathology, and they are the third most frequent upper-limb fractures, without seasonal variability in our area (temperate oceanic climate).

Older women who suffer a low-energy mechanism are the most affected.

Most fractures are displaced, and the number of complex fractures increases with the age of the population.

There has been an increase in the surgical treatment for these fractures in recent years, but it is not in accordance with the increase of complex fractures.

It is important to adopt measures in the ageing population in order to prevent PHF risk factors from becoming a new source of dependency for the elderly population.

\section{Acknowledgements}

Not applicable

\section{Authors' contributions}

All authors have contributed to the design, execution, data collection, and analysis of this study. They all have reviewed and confirmed substantially the accuracy of the whole manuscript. The authors read and approved the final manuscript.

\section{Funding}

This study has not received funding.

\section{Availability of data and materials}

The datasets used and/or analysed during the current study are available from the corresponding author on reasonable request

\section{Declarations}

Ethics approval and consent to participate

The study protocol was approved by the Autonomous Community Ethics Committee. The researchers conducted the study in accordance with the principles of the Declaration of Helsinki. The study was developed according to the protocol and in compliance with the standards of good clinical practice, as described in the guidelines of the International Council for Harmonisation (ICH) on good clinical practice.

The use of anonymized patient data for statistical and epidemiological study does not require their specific informed consent as it is considered an assessment of quality of care.

\section{Consent for publication}

Not applicable

\section{Competing interests}

The authors declare that they have no competing interests.

Received: 8 April 2021 Accepted: 10 June 2021

Published online: 22 June 2021

\section{References}

1. Bergdahl C, Ekholm C, Wennergren D, Nilsson F, Möller M. Epidemiology and patho-anatomical pattern of 2,011 humeral fractures: data from the Swedish Fracture Register. BMC Musculoskelet Disord. 2016;17(1):159. https://doi.org/10.1186/s12891-016-1009-8.

2. Roux A, Decroocq L, El Batti S, Bonnevialle N, Moineau G, Trojani C, et al. Epidemiology of proximal humerus fractures managed in a trauma center. Orthop Traumatol Surg Res. 2012;98(6):715-9. https://doi.org/10.1016/j.otsr.2 012.05.013.

3. Passaretti D, Candela V, Sessa P, Gumina S. Epidemiology of proximal humeral fractures: a detailed survey of 711 patients in a metropolitan area. J Shoulder Elb Surg. 2017;26(12):2117-24. https://doi.org/10.1016/j.jse.2017.05.029.

4. Court-Brown CM, Caesar B. Epidemiology of adult fractures: a review. Injury. 2006;37(8):691-7. https://doi.org/10.1016/j.injury.2006.04.130.

5. Launonen AP, Lepola V, Saranko A, Flinkkilä T, Laitinen M, Mattila VM. Epidemiology of proximal humerus fractures. Arch Osteoporos. 2015;10(1): 2-5. https://doi.org/10.1007/s11657-015-0209-4.

6. Kannus P. Palvanen M, Niemi S, Sievanen H, Parkkari J. Rate of proximal humeral fractures in older Finnish women between 1970 and 2007. Bone. 2009:44(4):656-9. https://doi.org/10.1016/j.bone.2008.12.007.

7. Palvanen M, Kannus P, Niemi S, Parkkari J. Update in the epidemiology of proximal humeral fractures. Clin Orthop Relat Res. 2006;442(87-92):5.

8. Bell JE, Leung BC, Spratt KF, Koval KJ, Weinstein JD, Goodman DC, et al. Trends and variation in incidence, surgical treatment, and repeat surgery of proximal humeral fractures in the elderly. J Bone Jt Surg Am. 2011;93(2): 121-31. https://doi.org/10.2106/JBJS.I.01505.

9. Pentek M, Horvath C, Boncz I, Falusi Z, Toth E, Sebestyen A, et al. Epidemiology of osteoporosis related fractures in Hungary from the nationwide health insurance database, 1999-2003. Osteoporos Int. 2008; 19(2):243-9. https://doi.org/10.1007/s00198-007-0453-6.

10. Kristiansen B, Barfod G, Bredesen J, Erin-Madsen J, Grum B, Horsnaes MW, et al. Epidemiology of proximal humeral fractures. Acta Orthop Scand. 1987; 58(1):75-7. https://doi.org/10.3109/17453678709146347.

11. Dimai HP, Svedbom A, Fahrleitner-Pammer A, Pieber T, Resch H, Zwettler E, et al. Epidemiology of proximal humeral fractures in Austria between 1989 and 2008. Osteoporos Int. 2013;24(9):2413-21. https://doi.org/10.1007/s001 98-013-2339-0.

12. Court-Brown CM, Garg A, McQueen MM. The epidemiology of proximal humeral fractures. Acta Orthop Scand. 2001;72(4):365-71. https://doi.org/1 $0.1080 / 000164701753542023$

13. Bahrs C, Stojicevic T, Blumenstock G, Brorson S, Badke A, Stöckle U, et al. Trends in epidemiology and patho-anatomical pattern of proximal humeral fractures. Int Orthop. 2014;38(8):1697-704. https://doi.org/10.1007/s00264014-2362-6

14. Müller ME, Nazarian S, Koch P, Schatzker J. The comprehensive AO classification of fractures of long bones. Berlin Heidelberg New York: Springer; 1990. p. 54-85.

15. Neer CS 2nd. Displaced proximal humeral fractures. I. Classification and evaluation. J Bone Jt Surg Am. 1970;52(6):1077-89. https://doi.org/10.2106/ 00004623-197052060-00001.

16. Rothman KJ. Epidemiology: an introduction. New York: Oxford University Press; 2002.

17. Kim SH, Szabo RM, Marder RA. Epidemiology of humerus fractures in the United States: nationwide emergency department sample, 2008. Arthritis Care Res. 2012;64(3):407-14. https://doi.org/10.1002/acr.21563.

18. Lind T, Krøner $K$, Jensen J. The epidemiology of fractures of the proximal humerus. Arch Orthop Trauma Surg. 1989;108(5):285-7. https://doi.org/10.1 007/BF00932316.

19. Maravicz M, Bihan CL, Landais $P$, et al. Incidence and cost of osteoporotic fractures in France during 2001. A methodological approach by the national hospital database. Osteoporos Int. 2005;16(12):1475-80. https://doi.org/10.1 007/s00198-005-2031-0.

20. Sumrein $B O$, Huttunen $T$, Launonen AP, Berg HE, Felländer-Tsai L, Mattila VM. Proximal humeral fractures in Sweden-a registry-based study. Osteoporos Int. 2017;28(3):901-7. https://doi.org/10.1007/s00198-016-3808-z. 
21. Hernlund E, Svedbom A, Ivergård M, Compston J, Cooper C, Stenmark J, et al. Osteoporosis in the European Union: medical management, epidemiology and economic burden. A report prepared in collaboration with the International Osteoporosis Foundation (IOF) and the European Federation of Pharmaceutical Industry Associations (EFPIA). Arch Osteoporos. 2013;8(1-2):136. https://doi.org/10.1007/s1 1657-013-0136-1.

22. Klug A, Gramlich Y, Wincheringer D, Schmidt-Horlohé K, Hoffmann R. Trends in surgical management of proximal humeral fractures in adults: a nationwide study of records in Germany from 2007 to 2016. Arch Orthop Trauma Surg. 2019;139(12):1713-21. https://doi.org/10.1007/s00402-019-03252-1.

23. Kleinlugtenbelt $\mathrm{Y}$, Bhandari M. Cochrane in CORR $\bullet$ : Interventions for Treating Proximal Humeral Fractures in Adults (Review). Clin Orthop Relat Res. 2015;473(9):2750-6. https://doi.org/10.1007/s11999-015-4430-7.

24. Calvo E, Morcillo D, Foruria AM, Redondo-Santamaría E, Osorio-Picorne F, Caeiro JR. Nondisplaced proximal humeral fractures: high incidence among outpatient-treated osteoporotic fractures and severe impact on upper extremity function and patient subjective health perception. J Shoulder Elb Surg. 2011;20(5):795-801 (ISSN: 1532-6500). https://doi.org/10.1016/j.jse.2010. 09.008.

25. Chu SP, Kelsey JL, Keegan TH, Sternfeld B, Prill M, Quesenberry CP, et al. Risk factors for proximal humerus fracture. Am J Epidemiol. 2004;160(4):360-7. https://doi.org/10.1093/aje/kwh224.

26. Martinez-Huedo MA, Jiménez-García R, Mora-Zamorano E, HernándezBarrera V, Villanueva-Martinez M, Lopez-de-Andres A. Trends in incidence of proximal humerus fractures, surgical procedures and outcomes among elderly hospitalized patients with and without type 2 diabetes in Spain (2001-2013). BMC Musculoskelet Disord. 2017;18(1):522. https://doi.org/10.11 86/s12891-017-1892-7.

27. Rangan A, Handoll H, Brealey S, Jefferson L, Keding A, Martin BC, Goodchild L, Chuang LH, Hewitt C, Torgerson D; PROFHER Trial Collaborators (2015) Surgical vs nonsurgical treatment of adults with displaced fractures of the proximal humerus: the PROFHER randomized clinical trial. JAMA. 313(10): 1037-1047. doi: 10.1001/jama.2015.1629.

28. Rabi S, Evaniew N, Sprague SA, Bhandari M, Slobogean GP. Operative vs nonoperative management of displaced proximal humeral fractures in the elderly: A systematic review and meta-analysis of randomized controlled trials. World J Orthop. 2015;6(10):838-46. https://doi.org/10.5312/wjo.v6.i10.838.

\section{Publisher's Note}

Springer Nature remains neutral with regard to jurisdictional claims in published maps and institutional affiliations.

Ready to submit your research? Choose BMC and benefit from:

- fast, convenient online submission

- thorough peer review by experienced researchers in your field

- rapid publication on acceptance

- support for research data, including large and complex data types

- gold Open Access which fosters wider collaboration and increased citations

- maximum visibility for your research: over $100 \mathrm{M}$ website views per year

At $\mathrm{BMC}$, research is always in progress.

Learn more biomedcentral.com/submissions 